\title{
Paneth Cell Metaplasia: An Ominous Finding
}

\author{
Parivash Badar* and Syed Mikhail Zaidi \\ Ziauddin University, Pakistan
}

*Corresponding author: Parivash Badar, Ziauddin University, Karachi, Pakistan.

Received Date: May 24, 2019

Published Date: May 28, 2019

\section{Introduction}

Discussion regarding the nature of paneth cell metaplasia has become increasingly popular over the last decade with respect to certain breakthrough studies emphasizing on the relationship between Inflammatory Bowel Disease and PCM. However, the incident of isolated paneth cell metaplasia in an otherwise unremarkable mucosa and asymptomatic patient has not been extensively studied [1]. A strong correlation has been established between distal PCM and the presence of newly diagnosed IBD in children [2]. Further it was emphasized that even though the presence of distal PCM is a marker for the presence of IBD in an individual, the presence of proximal PCM was seen to be nonspecific sign in adults however it has been established that repair and regeneration may be the most potent stimuli for PCM [3][4].

Not much work has been done regarding the incidence of paneth cell metaplasia in Pakistan neither any such correlations have been established amongst the masses. This leads to many speculations regarding the causal association between the various factors however chronic constipation and symptoms suggestive of IBD are present in our case of focus.

\section{Case Report}

48 year old lady who was treated for Hep C 2 years ago, was referred to the surgery department by her physician. She had been complaining of left iliac fossa pain for the last 2 months radiating to the pelvic area including the vagina and anus. She also complained of urgency and frequency during urination and a few episodes of incontinence. She presented with mild fever (99 F) throughout the day and lethargy and malaise.

Complete Blood Count showed slightly raised WBC (11.0) and her $\mathrm{D} / \mathrm{R}$ showed RBC positive $+\mathrm{U} / \mathrm{S}$ abdomen showed a single cortical cyst at the lower left pole of the kidney. After investigations her urologist diagnosed her with a UTI on the 1/4/16 and began treatment with cephalosporin and citralka syrup.

Even though the fever subsided the pain was still present and the patient was in discomfort and she came back on the in 3 months with more exaggerated complaints of abdominal pain and perineal tenderness. She also had two episodes of fecal incontinence during this time even though she has been otherwise constipated. Her constipation was chronic and was temporarily relieved by ispaghol or castor oil. She was admitted for a day in the hospital, at this time proctoscopy and sigmoidoscopy was done. Findings were not significant, noh hemorrhoids, no fissures, normal mucosa of the anus, rectum and sigmoid. Colonoscopy was advised and revealed bleeding $\mathrm{P} / \mathrm{R}$ and an ulcerative leassion at the ceacum. With multiple ulcers seen in transverse colon, mild to moderate proctitis seen in rectum.

\section{Discussion}

Paneth cells synthesize and secrete substantial quantities of antimicrobial peptides and proteins. More recent studies have determined that these antimicrobial molecules are key mediators of host-microbe interactions, including homeostatic balance with colonizing microbiota and innate immune protection from enteric pathogens. Another important function of Paneth cell is the secretion of factors that help sustain and modulate the epithelial stem and progenitor cells that cohabitate in the crypts and rejuvenate the small intestinal epithelium [5]. Keeping these potential stimulatory role of the paneth cells in mind it can be comprehended that the metaplasia of these cells can lead to the development of certain hyperplastic conditions such as adenomas or carcinoma formation. Hence, it would be progressive to use paneth cell metaplasia as an important tumor marker [4,6] Figure 1.

The presence of PCM with no histological features of chronicity, particularly in the early stages of IBD can be of paramount importance when it comes to treating such cases [2] Despite the advantage of this incidental finding there has been incidence of paneth cell metaplasia in the stomach, in the normal small intestine and in the large bowel with IBD, the question that this metaplasia may represent an example of the multipotential metaplastic capability of actively dividing cells is still a mystery and deserves to be investigated $[6,7]$. And the concept that further knowledge 
regarding their role will open up new therapeutic avenues for preventing infection as well as for causally treating inflammatory bowel diseases [8].

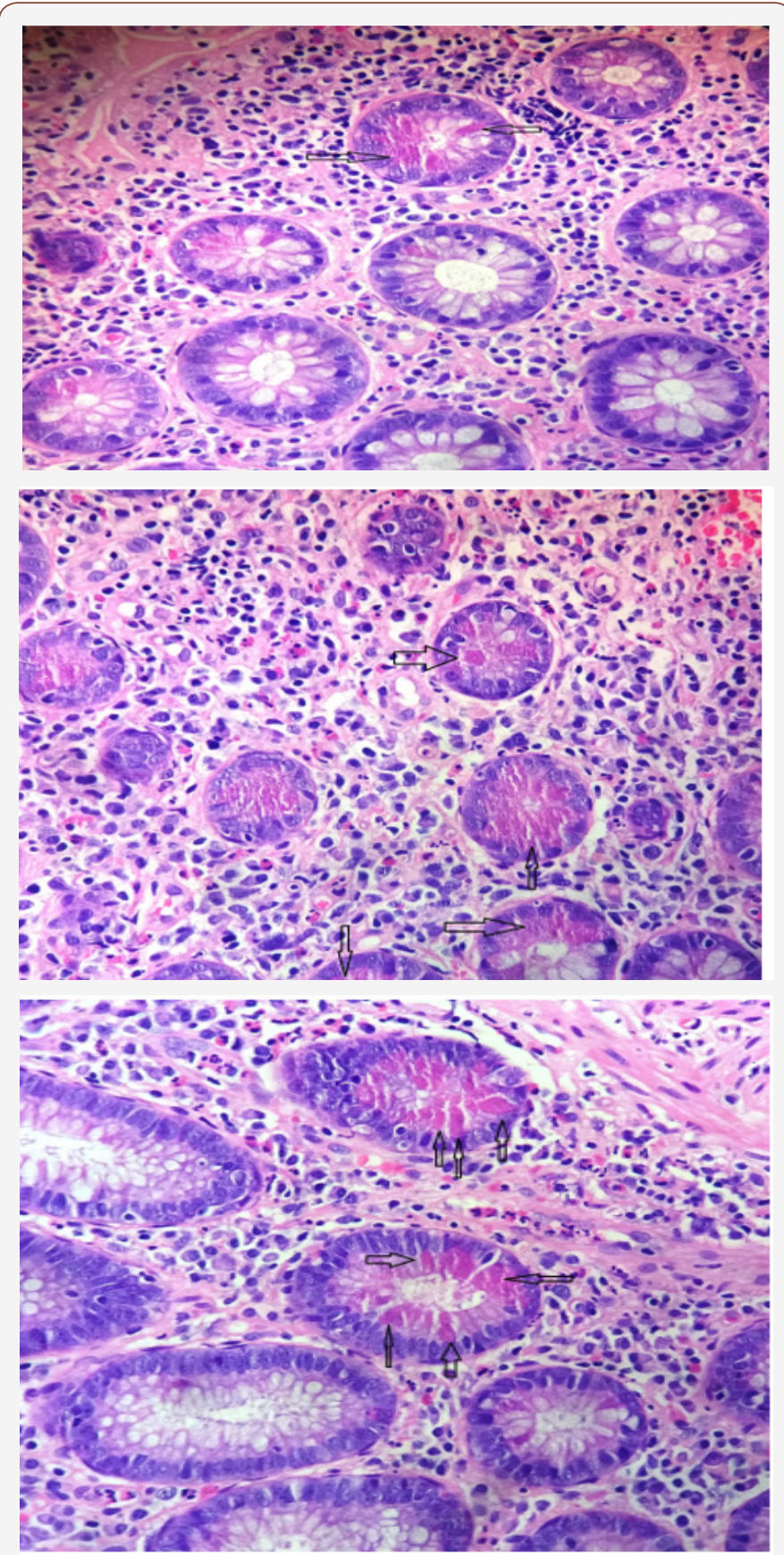

Figure 1: Images showing the presence of Paneth cells on biopsy

\section{Conclusion}

In our scenario, where this patient has come with extremely nonspecific signs of an inflammatory bowel disease or an actively observed adenoma it is interesting to note that paneth cell metaplasia can present as a benign condition and lead to the conclusion that there has been some exaggerated innate host defence mechanism played by these cells [9]. Hence, an unusual presentation follows that demonstrates the variability of its features and also the simplicity. This is the first reported case of paneth cell metaplasia in Pakistan and it derives more questions as to how this multipotential metaplastic condition is flourishing.

\section{Acknowledgement}

None.

\section{Conflict of Interest}

No conflict of interest.

\section{References}

1. Pezhouh MK, Cheng E, Weinberg AG, Park JY (2016) Significance of Paneth Cells in Histologically Unremarkable Rectal Mucosa. Am J Surg Pathol 40(7): 968-971.

2. Simmonds N, Furman M, Karanika E, Phillips A, Bates AW, et al. (2014) Paneth Cell Metaplasia In Newly Diagnosed Inflammatory Bowel Disease In Children. BMC Gastroenterol 14: 93.

3. Tanaka M, Saito H, Kusumi T, Fukuda S, Shimoyama T, et al. (2001) Spatial Distribution and Histogenesis Of Colorectal Paneth Cell Metaplasia in Idiopathic Inflammatory Bowel Disease. J Gastroenterol Hepatol 16(12): 1353-1359.

4. Wei Chen, Wendy L Frankel, Kevin M Cronley, Lianbo Yu, Xiaping Zhou, et al. (2015) Significance of Paneth Cell Metaplasia in Barrett Esophagus: A Morphologic and Clinicopathologic Study. American Journal of Clinical Pathology 143(5): 665-671.

5. Ganz T (2000) Paneth cells--guardians of the gut cell hatchery. Nat Immunol 1 (2): 99-100.

6. Rubio CA, Kanter L, Björk J, Poppen B, Bry L, et al. (1996) Paneth CellRich Flat Adenoma of The Rectum: Report Of A Case. 87(1): 109-112.

7. Frydman CP, Bleiweiss IJ, Unger PD, Gordon RE, Brazenas NV, et al. (1992) Paneth Cell-Like Metaplasia of The Prostate Gland. Arch Pathol Lab Med 116(3): 274-276.

8. Wehkamp J, Stange EF (2016) Paneth cells and the innate immune response. Curr Opin Gastroenterol 22: 644-650.

9. DA Elphick, YR Mahida (2005) Paneth Cells: Their Role in Innate Immunity and Inflammatory Disease. Gut 54(12): 1802-1809. 